\title{
As ideias econômicas de Mauá e o liberalismo nos trópicos $(1860-1878)^{1}$
}

\section{Mauá's economic ideas and liberalism in the Tropics (1860-1878)}

\author{
Thiago F. R. Gambi ${ }^{1,}$ * (D) 0000-0002-8011-3544 \\ Daniel V. Cosentino ${ }^{2}$ (iD 0000-0002-5891-6594
}

${ }^{1}$ Universidade Federal de Alfenas, Alfenas, Brasil.

${ }^{2}$ Universidade Federal de Ouro Preto, Ouro Preto, Brasil.

* Correspondencia: thiago.fontelas@gmail.com

Resumo. O objetivo deste texto é analisar as ideias de Mauá sobre o progresso econômico, a moeda e o crédito, e o câmbio, a partir de seu depoimento ao relatório oficial sobre a crise de 1857, dos artigos que escreveu sobre o meio circulante intitulados "Questões econômicas: a situação monetária do Brasil", publicados no Jornal do Comércio em abril de 1878, e, finalmente, de sua Autobiografia. Avaliaremos como a realidade brasileira da época e os próprios negócios de Mauá moldaram suas ideias econômicas e, ao mesmo tempo, como essas ideias apareceram no debate econômico, a fim de influenciar os rumos da política econômica do Império. A análise procurará mostrar como Mauá, uma figura típica de seu tempo, foi capaz de produzir ideias econômicas coerentes que espelham tanto sua filosofia liberal como a prática dos negócios e da política imperial.

CÓMO CITAR: Gambi, T. F. R. e Cosentino, D. V. (2020). As ideias econômicas de Mauá e o liberalismo nos trópicos (18601878). America Latina en la Historia Económica, 27(1), e1014. DOI: 10.18232/alhe.1014

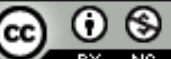

${ }^{1}$ Este artigo é uma versão revista do trabalho “As ideias de Mauá sobre o progresso econômico, a moeda e o crédito, e o câmbio (1860-1878)”, apresentado no XII Congresso Brasileiro de História Econômica e $13^{\text {a }}$ Conferência Internacional de História de Empresas realizado em 2017.

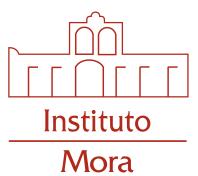


Palavras-chave: progresso econômico; moeda; crédito; câmbio.

Abstract. The aim of this paper is to analyze the ideas of Mauá on the economic progress, the money and credit, and the exchange rate. Three sources were used to do so the report of the crisis of 1857 , the articles "Economic issues: Brazil's monetary situation", published in the Jornal do Comércio in 1878 and, finally, his Autobiography. We will evaluate how the Brazilian reality and their own businesses shaped the economic ideas of Maua and, at the same time, how these ideas appeared in the economic debate, in order to influence the direction of economic policy of the empire. The analysis shows how Mauá, a typical figure of his time, was able to produce consistent economic ideas that reflect both his liberal philosophy and business practice and imperial policy.

Key words: economic progress; currency; credit; exchange rate.

JEL: B19; N16; N96.

Recebido: 17 de agosto de 2018.

Aceito: 24 de otubro de 2018.

Publicado: 13 de setembro de 2019.

Organização colaboradora: Fundação de Amparo à Pesquisa de Minas Gerais, Brasil.

\section{INTRODUÇÃO}

Mauá é, sem dúvida, uma das figuras mais conhecidas e estudadas do império brasileiro. Diversos autores de diferentes épocas o retrataram sob diversos pontos de vista. Ele pode ser visto, por um lado, como pioneiro do empreendedorismo; como o espírito da livre iniciativa contra as retrógradas amarras da monarquia imperial; como defensor da indústria e dos interesses do país. Heitor Ferreira Lima (1976), Lídia Besouchet (1978) e, mais contemporaneamente, Jorge Caldeira (1995), o veem como o progressista, o emancipador, o pioneiro da indústria, em suma, a personificação da aspiração capitalista e, portanto, representante da vanguarda do desenvolvimento econômico da época. Entretanto, forças políticas internas e externas que se sentiam ameaçadas com o seu avanço teriam sabotado suas iniciativas e levado ao seu melancólico fim. A visão de Mauá como herói do progresso econômico que lutava contra a opressão do Estado imperial dominado por escravocratas cristalizou-se ao longo do tempo transformando-o numa espécie de mito conveniente ao discurso liberalizante e individualista, e, posteriormente, industrialista (Souza, 2007).

Por outro lado, há autores que enxergam em Mauá a encarnação do enriquecimento por meio do tráfico negreiro, a infiltração do interesse privado no seio da política e do Estado, e a representação dos interesses comerciais ingleses. Embora muitas vezes apresentado como crítico da escravidão e vítima do Estado imperial e do imperialismo inglês, Carlos G. Guimarães (2012) nos lembra de sua ligação com os ingleses por meio de relações pessoais e de sua casa comercial, do envolvimento dessa casa com o tráfico negreiro e ainda de suas relações com membros da elite dos partidos conservador e liberal no interior do Estado imperial. Flávio Saes (1987), apesar de destacar seu pioneirismo na indústria e na construção de ferrovias, também relativiza o mito Mauá ao vincular sua trajetória a da própria economia mercantil e escravista do Império. A modernidade capitalista expressa em Mauá seria uma resposta à crise dessa economia e o limite de seus negócios era dado pela incapacidade dessa mesma economia de gerar um mercado interno suficiente para 
lhe dar suporte. Embora seus negócios pudessem ter ferido interesses do Estado imperial e do capital inglês, Mauá manteve relações próximas tanto com o primeiro, que lhe outorgou os títulos de barão e visconde, quanto com o segundo, com quem mantinha relações comerciais e financeiras.

Os Paradoxos de um visionário, livro organizado para comemorar o bicentenário de seu aniversário, parecem traduzir a complexidade que enxergamos em sua trajetória e em suas ideias econômicas, assim como o sentimento misto de admiração e crítica verificado em obras sobre sua vida (Souza e Fossatti, 2013). Seja admirado ou criticado, essa amostra de trabalhos sobre Mauá revela sua importância na história do Brasil e o interesse que até hoje desperta nos pesquisadores. Embora sejam muitos os estudos sobre esse personagem, realizados em contextos e épocas distintas, é notável a lacuna na análise de suas ideias econômicas, exceção feita ao trabalho de Fernandes (1974).

Charles Kindleberger (2000) considerou a agrura econômica de 1857 como a primeira crise capitalista de alcance internacional. Começou no Estados Unidos e alcançou o Brasil, onde fez estragos na economia e vítimas na política com a queda do gabinete Olinda2-Souza-Franco. Este último foi ministro da Fazenda e adotou a pluralidade de emissão no Império. Quando caiu, havia reformado o sistema monopolista de moeda e crédito levado a efeito anteriormente pelo visconde de Itaboraí. O gabinete que o substituiu, com Abaet $\mathrm{S}^{3}$ na chefia e Inhomirim $4^{4}$ na Fazenda, tentou implementar uma contra reforma para retornar ao sistema monopolista que acabou levando à sua rápida dissolução. Uruguaiana ${ }^{5}$ assumiu, então, a chefia de gabinete e o ministério da Fazenda entre a reforma de Souza Franco e a contra reforma de Inhomirim (Gambi, 2015a). Hesitante, em 1859, nomeou uma comissão de inquérito para avaliar as causas da crise que afetara a economia brasileira dois anos antes e apontar o rumo da sua política econômica. Mauá foi um dos negociantes entrevistados neste relatório e, por isso, seu depoimento de dois de março de 1860 constitui o marco inicial desta pesquisa.

\footnotetext{
${ }^{2}$ Pedro Araújo Lima nasceu em 1793, em Antas, Pernambuco. Formado em Coimbra, doutorou-se em Cânones (1819). Foi regente do império (1837), deputado (1821) e senador (1837) por Pernambuco. Ocupou o ministério do império (1823, 1827 e 1837), o ministério da justiça e interinamente o dos estrangeiros (1832) e a chefia de gabinete (1848, 1857, 1862 e 1865). Nomeado para o conselho de Estado em 1842, faleceu no Rio de Janeiro em 1870 (Vasconcellos e Smith, 1918, pp. 317-318).

${ }^{3}$ Antônio Paulino Limpo de Abreu nasceu em Lisboa, em 1798. Formado em Direito pela Universidade de Coimbra, exerceu todos os cargos da magistratura brasileira. Deputado (1826) e senador (1847) por Minas Gerais, foi também presidente dessa província (1833). Foi doze vezes ministro de Estado e nomeado conselheiro em 1848. Faleceu no Rio de Janeiro, 1883 (Vasconcellos e Smith, 1918, pp. 24-25).

${ }^{4}$ Francisco de Salles Torres Homem nasceu no Rio de Janeiro, em 1812. Doutor em Medicina pela Faculdade do Rio de Janeiro e em Direito pela Universidade de Paris. Foi secretário de legação e encarregado de negócios em Paris. Foi deputado (1848) por Minas Gerais e senador (1870) pelo Rio Grande do Norte. Ocupou ainda os cargos de diretor de Rendas Públicas e presidente do Banco do Brasil. Nomeado para o conselho de Estado em 1866, faleceu em Paris, em 1876 (Vasconcellos e Smith, 1918, pp. 191-192).

${ }^{5}$ Ângelo Muniz da Silva Ferraz nasceu em Valença, Bahia, em 1812. Formado em Direito pela Faculdade de Olinda, foi promotor, juiz de direito e inspetor da alfândega da Corte (1848). Foi deputado (1843) e senador (1856) pela província da Bahia. Em 1857, presidiu a província do Rio Grande do Sul. Ocupou o ministério da fazenda e a chefia de gabinete (1859), o ministério da guerra (1865) e o ministério da marinha (1866). Foi nomeado para o conselho de Estado em 1866 e faleceu em Petrópolis, em 1867 (Vasconcellos e Smith, 1918, pp. 520-521).
} 
Aos 65 anos de idade, em 1878, falido, Mauá escreveu sua Autobiografia. Além de descrever seu legado empresarial, era uma oportunidade para explicar seus feitos aos acionistas das empresas ligadas a ele e responder à série de acusações que sofria naquele momento. Entre seus feitos empresariais estava o Banco Mauá \& Cia. a partir do qual fez apreciações sobre a moeda e o crédito no Brasil. Por isso, o ano em que escreveu sua Autobiografia encerra o período de investigação.

Em síntese, o objetivo deste trabalho é verificar o que pensava Mauá sobre o progresso econômico, a moeda e o crédito, e o câmbio, a partir de seu depoimento ao relatório oficial sobre a crise de 1857, dos artigos que escreveu sobre o meio circulante intitulados "Questões econômicas: a situação monetária do Brasil”, publicados no Jornal do Comércio em abril de 1878, posteriormente compilados em $O$ meio circulante do Brasil, e, finalmente, de sua Autobiografia ${ }^{6}$

Neste artigo, aprofundaremos a análise de suas ideias econômicas tentando sistematiza-las; situaremos sua posição no contexto das disputas políticas do Império e de sua atuação em diversos empreendimentos, inclusive bancos. Além disso, no decorrer da análise, consideraremos subsidiariamente sua experiência como negociante, sua relação com os ingleses e tentaremos identificar suas influências teóricas.

Seria possível falar num pensamento econômico de Mauá? Pode-se dizer que suas ideias sobre moeda e crédito eram coerentes e articuladas a uma concepção de desenvolvimento do Império. Mirava a realidade brasileira, suas dificuldades e potencialidades, com notável clareza quanto à especificidade da economia do país. Nesse sentido seu pensamento econômico se afirma (Cosentino, 2016), mas não é esta a questão essencial a nosso ver. O importante seria verificar como a realidade brasileira da época e seus próprios negócios moldaram suas ideias econômicas e, ao mesmo tempo, como essas ideias apareceram no debate econômico, a fim de influenciar os rumos da política econômica imperial, caso do período em que Souza Franco estava no ministério da Fazenda e, especialmente, durante a crise de 1857, quando houve um movimento de desvalorização da moeda brasileira.

Portanto, a pergunta que guia o artigo é: quais as ideias de Mauá sobre o progresso econômico, a moeda e o crédito, e o câmbio, e sua posição no debate econômico da segunda metade do XIx? Tentaremos mostrar, nos limites dos textos analisados, como Mauá foi uma figura típica de seu tempo, capaz de produzir ideias monetárias coerentes que espelham tanto sua filosofia liberal como a prática dos negócios e da política imperial.

\section{Progresso ECONÔMICO}

O contato precoce de Mauá com os negócios é bastante conhecido. Vindo do Rio Grande do Sul, onde nasceu, chegou ao Rio de Janeiro no ano da independência quando contava nove anos de idade. Conseguiu trabalho como caixeiro na casa comercial do negociante de grosso português, senhor de engenho e fazendeiro de café João Rodrigues Pereira de Almeida, barão de Ubá. Depois exerceu a mesma função na casa comercial Carruthers \& Co. dirigida pelo negociante inglês Richard Carruthers, de quem se tornaria sócio. Ambas as casas, entre outras coisas, negociavam

\footnotetext{
${ }^{6}$ Motta (2000) adverte para o risco da imprecisão e subjetividade embutido no uso da biografia como fonte. No entanto, avaliamos que esse risco é maior quando se trata de apreender toda uma realidade social por meio da memória de um indivíduo. Nesta pesquisa, a Autobiografia se revelou uma fonte apropriada, já que seu objetivo se circunscreveu à análise das ideias econômicas de Mauá. Note-se ainda que o objetivo do visconde com esse livro era fazer uma exposição aos seus credores. O termo Autobiografia foi acrescentado ao título somente em sua primeira reedição de 1942 (Souza, 2005).
} 
escravos. Era comum, nas décadas de 1830 e 1840, a associação entre traficantes de escravos brasileiros e firmas da Europa e Estados Unidos (Tavares, 1988; Martinho e Gorestein, 1993; Guimarães, 2012).

Ao contrário de dois de seus principais interlocutores no debate econômico, Mauá não teve formação acadêmica. Souza Francd 7 era formado em direito pela faculdade do Recife e, por meio desse curso, entrou em contato com a economia política. Itabora 8 formou-se em matemática pela universidade de Coimbra e estudou economia mais intensamente quando assumiu o ministério da Fazenda pela segunda vez em 1848 (Macedo, 1876). Já Mauá adquiriu seus conhecimentos na prática dos negócios, sobretudo com Carruthers (Ganns, 2011). A ausência de uma educação formal, todavia, não o impediu de pensar o progresso econômico do país e questões econômicas específicas que interfeririam nessa marcha.

Mauá moldaria sua visão do país e suas ideias econômicas num heterogêneo caldo de referências que misturavam o ímpeto burguês e a nobreza imperial, que o vinculava ao Estado; a liberdade de iniciativa e o tráfico de escravos, que o colocava em contato com a base econômica e social do Império; a monocultura brasileira e a indústria inglesa, que o apresentava à vanguarda do capitalismo na época. E não ficou alheio à influência dos clássicos ingleses. Ele compartilhava com esses economistas a ideia de que a riqueza de um país estava na produção e não no acúmulo de metais, uma noção anacrônica segundo ele mesmo (Brasil, 1860, p. 96).

Do mesmo modo, aceitava a visão fundamental de que a livre iniciativa individual seria o motor da realização do interesse social (Mauá, $2011 \mathrm{a}$, p. 106) e, nesse sentido, o interesse dos homens de negócio do Império se coadunariam com o interesse do país e, por conseguinte, do Estado. A associação de iniciativas individuais seria força ainda mais eficaz para impulsionar o progresso econômico ao reunir capitais dispersos, inclusive territorialmente, e valorizá-los por meio do investimento em grandes empreendimentos como ferrovias, telégrafos e iluminação pública (Mauá, 2011a, p. 128, nota 33) 9

Já passada sua experiência de sucessos e fracassos nos negócios, Mauá avaliou que, no Brasil, funcionava a lógica inversa, isto é, que os interesses do Estado e dos homens de negócio seriam contraditórios (Mauá, 2011a, p. 118). Isso significava que o Estado, no afã de controlar a atividade

\footnotetext{
${ }^{7}$ Bernardo de Souza Franco nasceu em Belém, Pará, em 1805. Formado em Ciências Jurídicas e Sociais pela Academia de Olinda. Foi juiz de direito e desembargador. Presidiu as províncias do Pará (1839), de Alagoas (1844) e do Rio de Janeiro (1864). Foi deputado (1838) e senador (1855) pela província do Pará. Foi ministro dos negócios estrangeiros (1848) e da fazenda (interino em 1848 e efetivo em 1857). Faleceu no Rio de Janeiro em 1875 (Vasconcellos e Smith, 1918, p. 486).

${ }^{8}$ Joaquim José Rodrigues Torres, visconde de Itaboraí a partir de dezembro de 1854, nascido em Porto de Caxias, província do Rio de Janeiro, formou-se em matemática na Universidade de Coimbra. Depois de formado, voltou à Europa para estudar na França. Foi deputado de 1834 a 1843 e senador de 1844 a 1872, ano de sua morte. Foi presidente da província do Rio de Janeiro entre 1834 e 1836. Como professor, lecionou na Academia Militar. Como jornalista, fundou e redigiu o periódico Independente, quando ainda defendia princípios liberais. Foi parlamentar e membro do conselho de Estado. Desde que assumiu o ministério da marinha em 1831 influenciou ativamente a direção do governo imperial. Passou pelos ministérios do Império, da Guerra e da Fazenda em gabinetes diversos. Com toda experiência política e administrativa acumulada em vinte anos de carreira pública, foi presidente do conselho de ministros em 1852 e 1868. Em 1852, propôs a criação do segundo Banco do Brasil, cuja presidência ocupou entre 1855 e 1857, e, depois de um interregno que correspondeu à passagem de Souza Franco pelo ministério da Fazenda, entre 1858 e 1859 (Vasconcellos e Smith, 1918, p. 200).

${ }^{9}$ Há um debate relativamente extenso sobre o caráter saint-simoniano do pensamento de Mauá. De um lado, há os que o identificaram com o socialista francês: Faria (1933), Carneiro (1965), Carvalho (1997). De outro, os que discordavam: Rebello (1975), Ganns (2011).
} 
econômica e tributar, acabava prejudicando a livre iniciativa individual. Mauá lamentava sua falta no Império, por exemplo, no caso da construção de diques no porto do Rio de Janeiro (Mauá, 2011a, p. 155), e criticava as leis preventivas e a própria intervenção do Estado nos casos em que havia associação de capitais (Mauá, 2011a, p. 208).

As leis preventivas eram aquelas que constrangiam a liberdade de associação ou aplicação do capital em casos que, de acordo com ele, deveriam ser regulados pelas convenções ou pelo mercado, e não pelo Estado (Mauá, 2011a, pp. 219-220). De fato, Mauá sofreu os efeitos dessas leis e da interferência estatal especialmente em seus bancos. Após a fusão do Banco do Brasil com o Banco Comercial do Rio de Janeiro fomentada pelo Estado em 1853 (Gambi, 2015a), as leis preventivas no campo da moeda e do crédito limitaram especialmente a atuação do Mauá, MacGregor, de 1854, no qual houve uma intervenção direta para alterar sua organização (Guimarães, 2012).

Por isso, ao mesmo tempo em que mantinha relações com o Estado e os partidos políticos, criticava-os por produzir leis preventivas contrárias à liberdade e, portanto, à criação de riqueza, em sua perspectiva, a pedra angular em que se assentava a civilização moderna (Mauá, 2011a, p. 221). A ideia de que a iniciativa individual levaria ao interesse social traz em si uma visão negativa da intervenção do Estado nos moldes da crítica dos clássicos à política mercantilista do século XVIII, em consonância com o pensamento econômico produzido na terra da revolução industrial. ${ }^{10}$

A indústria propriamente dita era outro ponto importante na visão de Mauá sobre o progresso econômico. É preciso lembrar que ele visitou a Inglaterra pela primeira vez em 1840 e foi convidado por John Morgan para conhecer uma fundição (Mauá, 2011a, p. 110). Esse empreendimento era o que ele imaginava ser uma das condições para o surgimento da indústria no Brasil. De fato, não é difícil associar Mauá à indústria como faz o título do livro de Heitor Ferreira Lima (1976) Três industrialistas brasileiros: Mauá, Rui Barbosa, Simonsen, contudo, a partir dos textos analisados, não é possível afirmar que, para Mauá, a indústria seria uma condição essencial para o progresso econômico. Aparentemente, ao falar de indústria e ao constituir suas próprias indústrias, ele não tinha em mente um processo de industrialização, mas a opinião de que o Brasil precisava de alguma indústria que pudesse se desenvolver sem grande auxílio do Estado para ajudar em seu progresso econômico (Mauá, 2011a, p. 110).

Nesse caso, é possível perceber a influência da economia política clássica inglesa, pois não se tratava necessariamente de alterar estruturalmente a economia brasileira de base agrícola e mercantil, mas de dar condições adequadas para o funcionamento do mercado e, eventualmente, para o surgimento de indústrias propriamente ditas que pudessem se manter autonomamente. Quanto à força de trabalho para operá-las, apesar de utilizar escravos em seus empreendimentos, Mauá adotava uma postura crítica à escravidão, em consonância com o espírito liberal da época.

O problema era justamente aplicar a defesa do liberalismo, a promoção da indústria e a crítica da escravidão num país cuja economia era basicamente agrária, mercantil e escravista. A análise da difusão e assimilação do liberalismo econômico no Brasil remonta a Cairu no início do século XIX (Paim, 1968; Rocha, 1996; Novais e Arruda, 2003; Furtado, 2007). Nota-se nele, assim como em Mauá, a dificuldade de adaptação e aplicação do pensamento econômico liberal à realidade econômica e social brasileira baseada na escravidão.

\footnotetext{
${ }^{10}$ A principal referência talvez seja Adam Smith em A riqueza das nações com a metáfora da mão invisível, a construção do bem coletivo a partir da ação individual egoísta e a interpretação crítica da política mercantilista articulada a partir do Livro 4.
} 
Em sua Autobiografia, Mauá reconstitui as histórias dos seus empreendimentos. Em praticamente todos, ou pelo menos nos mais importantes, há algum tipo de participação do Estado. Tomemos o caso do estaleiro Ponta d'Areia. Há menção de empréstimos feitos pelo Estado ao estaleiro (Mauá, 2011a, p. 115) 11 aparentemente, muitas de suas encomendas eram feitas pelo Estado (Mauá, 2011a, p. 116); o mesmo Estado tornou a legislação sobre artefatos de ferro mais liberal entre 1857 e 1860, justamente quando o grupo político ligado a Mauá estava na direção do Império. ${ }^{12}$ A finalização da estrada de ferro Santos-Jundiaí também contou com empréstimo estatal (Mauá, 2011a, p. 169) 13

Subvenções públicas aos empreendimentos de Mauá eram debatidas frequentemente no parlamento, como as concedidas à companhia de navegação do Norte (Mauá, 2011a, pp. 143ss), assim como a participação indireta do Estado em seus negócios por meio da concessão de garantia para empréstimos e captação de recursos no exterior. Foi o caso, por exemplo, da estrada de ferro que ligaria Recife a São Francisco ${ }^{14}$ De acordo com Mauá, essa garantia o salvou de um significativo prejuízo (Mauá, 2011a, pp. 150-151). Além disso, eram comuns também os pedidos de garantia de juros por tempo determinado, como no caso da estrada de ferro de Petrópolis (Mauá, 2011a, p. 136).

Apesar de defender a livre iniciativa e o espírito de associação, Mauá não era simpático à concorrência em seus negócios. Reclamou da competição com similares estrangeiros no caso da Ponta d'Areia (Mauá, 2011a, p. 114), criticou a concessão dada pelo Estado a outro empresário para construir uma estrada de ferro alternativa ligando o Rio de Janeiro a Petrópolis (Mauá, 2011 a, p. 140) e deteve o privilégio exclusivo da navegação no Amazonas (Mauá, 2011a, p. 141). Esses exemplos ilustram a relação de Mauá com o Estado e como o ideal capitalista inglês se concretizava nos limites do Brasil. A dependência relativa que seus negócios tinham do Estado e as restrições à concorrência não combinavam com o discurso da livre iniciativa individual e do liberalismo de maneira mais ampla, embora Mauá sempre as justificasse por meio da identificação de seu interesse pessoal com os interesses do Império.

Como dissemos, os princípios liberais que vicejavam na Inglaterra enfrentariam tensões quando aplicados nos trópicos. Mauá foi somente mais um exemplo da expressão dessas tensões, por isso, não surpreende o discurso de viés empresarial que apontava o Estado como obstáculo à livre iniciativa e a prática de se aproveitar do público para proteger interesses privados e atingir objetivos pessoais. No caso específico de Mauá, a explicação para o distanciamento entre discurso e prática reside, a nosso ver, primeiro, justamente no choque entre os princípios liberais e a realidade da economia brasileira. Não seria possível aplicá-los imediatamente numa economia escravista e numa sociedade de Corte. O próprio Mauá argumenta que a aplicação de princípios da economia clássica não seria adequada em países onde as causas que determinam os fenômenos econômicos fossem diversas (Mauá, 2011b, p. 281). Em seguida, seria preciso considerar seu interesse específico em cada negócio, pois o liberalismo de Mauá extraído de sua Autobiografia era eminentemente pragmático.

\footnotetext{
${ }^{11}$ Decretos 510, de 2 de outubro de 1848 e 933, de 26 de agosto de 1857.

${ }^{12}$ Momesso $(2007$, p. 65) reafirma os benefícios concedidos pelo Estado ao estaleiro entre 1848 e 1852 atribuindolhes à boa relação de Mauá com membros do gabinete conservador chefiado por Olinda.

${ }^{13}$ Sobre a relação deste empreendimento de Mauá com o Estado, ver Petratti (1977).

${ }^{14}$ Decreto 1629 , de 11 de agosto de 1855.
}

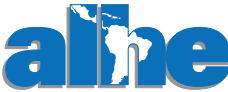


Numa economia escravista e numa sociedade de Corte, as motivações capitalistas ainda não estavam claramente definidas. O problema da escravidão estava associado frequentemente à restrição de oferta de força de trabalho e não ao limite que representava à constituição de um mercado interno. Comerciantes urbanos faziam parte da elite do Segundo Reinado, por isso, títulos de nobreza eram objetos de motivação tão ou mais fortes que o lucro no comércio. Mauá recebeu o título de barão em 1854 e o de visconde em 1874 aparentemente em troca de favores prestados ao Império, como no caso do cabo submarino (Mauá, 2011a, p. 195) e dos investimentos no Uruguai (Mauá, 2011a, p. 125).

Contudo, ele parecia de fato carregar a bandeira da modernidade econômica ao mostrar conhecimento teórico em relação ao lucro como motivador do progresso econômico. Era clara a percepção de que ganho e risco eram uma condição para a aplicação do capital. Para que este fosse colocado em movimento e gerasse riqueza seria preciso dar-lhe em retorno uma renda proporcional ao risco que pudesse ser razoavelmente previsto. Quanto maior o risco do empreendimento, maior deveria ser o lucro para o capitalista e o juro para o rentista (Mauá, 2011a, pp. 145ss).

A visão do progresso econômico de Mauá passava então pela motivação do ganho e pela liberdade de iniciativa individual e associação para obtê-lo. Era preciso, portanto, criar condições concretas para o florescimento da produção, seja industrial ou agrícola, e o debate sobre quais seriam essas condições levou Mauá a pensar sobre a moeda, o crédito e o câmbio.

\section{MOEdA E CRÉDITO}

O debate econômico no Brasil do século xix foi marcado pelas questões relativas à moeda e ao crédito. Havia nele, basicamente, três posições e duas delas espelhavam, ainda que de maneira adaptada (Saes, 1986; Gremaud, 1997), a controvérsia inglesa entre as escolas bancária e monetária (O’Brien, 2007; Fonseca e Mollo, 2012).

Discutia-se, em primeiro lugar, a conversibilidade da moeda, ou seja, se deveria ser feita em metal; em ativos de outra espécie; se deveria ser um misto de metal e outros ativos; ou não haver lastro definitivamente. Segundo, se a emissão de moeda deveria ser um monopólio e se este deveria ser público ou privado; se a emissão deveria ser livre, feita por bancos privados, mas regulados pelo Estado; ou se deveria ser inteiramente livre.

Para uns, a conversibilidade em metal seria condição fundamental para a estabilidade do valor da moeda nacional e, portanto, do progresso econômico. Desse modo, emissões e bancos deveriam ser estritamente controlados pelo Estado. Para outros, mais importante do que a sound currency, era garantir que a oferta de moeda suprisse a demanda de meios de circulação e crédito, e servisse como motor das transações. Portanto, com emissões e bancos mais livres do controle estatal haveria maior progresso econômico.

Itaboraí poderia ser encaixado no primeiro grupo e Souza Franco no segundo, mas há controvérsia quanto à posição de Mauá. Segundo Ganns (2011), o conselheiro Pereira da Silva (2003) inaugurou a crítica de que Mauá era um advogado do crédito ilimitado. Foi seguido por Taunay (1948) para quem Mauá apregoava as vantagens da pluralidade bancária e do direito lato às emissões. Na mesma linha, Joaquim Nabuco (1998) o considerava "um espírito sempre entrenublado pelas ficções do papel-moeda”, assim como Gustavo Barroso (1938) sustentava que Mauá era defensor de um "carnaval financeiro". Estabelecia-se assim a visão de que Mauá seria um partidário do papel-moeda inconversível e da liberdade bancária. 
Mais recentemente, Amaury Gremaud (1997) e André Villela (1999) avaliaram que Mauá iria mesmo além da escola bancária inglesa ao defender a ausência de lastro metálico em última instância. Essa posição o distanciaria inclusive de Souza Franco, sendo este um adepto do princípio bancário e o primeiro um papelista puro.

Já Alberto de Faria (1933, p. 253), na tentativa de mudar essa visão que considerava distorcida, defende a ideia de que Mauá nunca teria sido um partidário do papel-moeda ou de emissões inconversíveis. Prova disso seria a atuação de seu banco no Uruguai, que realizava a conversão de suas notas à vista e em ouro; e o fato de Mauá nunca ter solicitado ao Estado emissão para seus bancos.

A prova não convence muito, uma vez que os bancos de Mauá tinham que se submeter à legislação dos países em que atuavam, e se a conversibilidade em metal fosse exigida, eles assim teriam que proceder, mesmo que seu proprietário discordasse da exigência. É preciso lembrar ainda que Mauá tentou fugir da regulamentação estatal, inclusive sobre emissões, ao criar o Mauá, MacGregor como uma sociedade em comandita por ações e não como sociedade anônima. Ele aproveitaria brechas legais para fazer emissões, mesmo porque sabia, pelo menos entre $1853 \mathrm{e}$ 1864, com exceção do biênio 1857 e 1858, que não haveria espaço para solicitar emissão enquanto vigorasse o monopólio do Banco do Brasil.

Alberto de Faria (1933) talvez nem precisasse de exemplos para sustentar seus pontos. Bastaria citar o próprio Mauá que, em seus artigos sobre o meio circulante, dizia-se contrário ao livre arbítrio em matéria de moeda e bancos e favorável a medidas restritivas (Mauá, 2011b, p. 287). Porém, a nosso ver, é preciso considerar cuidadosamente essa posição, já que poderia significar uma precaução contra ataques dos adversários no debate monetário, e mais, formalizar o papelmoeda fiduciário no país enfrentaria resistências talvez intransponíveis não só entre os defensores do metal, mas também entre aqueles que defendiam o papel-moeda com lastro em ativos de outra espécie.

Apesar da interpretação de Alberto de Faria (1933), a leitura das fontes utilizadas neste artigo parece não deixar dúvida de que Mauá era um defensor do crédito e, portanto, crítico da conversibilidade em metal e do monopólio de emissão (Mauá, 2011a, p. 208). A questão é saber se advogava um papel-moeda conversível em ativos que não o metal ou o papel-moeda inconversível.

Mauá via o crédito como uma alavanca para os negócios nas sociedades desenvolvidas e, assim como pensava Souza Franco (Gambi, 2015b), seria fundamental no Brasil para converter um abundante capital inerte em instrumentos de produção (Mauá, 2011a, p. 216). Teoricamente, mesmo que o crédito não fosse considerado em si capital, seria criador de capital.

Com essa visão do crédito, Mauá entrou no negócio de banco em 1850, entretanto, não se pode perder de vista que ele se aproveitou naquela ocasião da disponibilidade de capitais liberados pelo fim do tráfico negreiro e da conveniência de ter um banco para eventualmente financiar seus outros negócios.

Claúdio Ganns (2011, p. 85) afirma que, com seus bancos, Mauá levaria capital para a atividade industrial. Contudo, a análise dos descontos feitos tanto pelo Banco do Brasil quanto pelo Mauá, MacGregor, realizada por Guimarães (2012, p. 176), indica que seu crédito era quase integralmente destinado a operações comerciais. De acordo com o autor, a atuação do banco revelava mais a permanência de uma "cultura de negócios" mercantil do que uma forma de atuação do capital financeiro ou de um conglomerado. Este é para nós um indício de que Mauá preocupava-se antes com o crédito para o aumento da produção, mesmo que agrícola, e do comércio no Brasil do que propriamente com sua industrialização. 
E o crédito estava intimamente ligado à moeda. Apesar das divergências quanto à posição de Mauá sobre a moeda, há concordância quanto à sua crítica à moeda metálica, segundo Fernandes (1974), uma crítica científica ao padrão-ouro. Distinguimos quatro argumentos que a embasam. Primeiro, a moeda metálica desviava recursos da produção, uma vez que se teria de direcionálos para a compra de metais, e depois esses metais ficariam parados como fundo de reserva dos bancos.

Segundo, ela não tinha elasticidade suficiente para atender o aumento da demanda por moeda e crédito no país. Com a moeda metálica, a regra seria a escassez de meio circulante e de recursos para empréstimos. A situação seria ainda mais grave em caso de crise, quando haveria saída de metais e, consequentemente, encolhimento da oferta monetária.

Terceiro, dadas as condições da economia brasileira, Mauá avaliava como impraticável a conversibilidade metálica, a não ser em momentos excepcionais. De acordo com ele, haveria duas alternativas impostas pela razão e pela ciência para se ter moeda metálica no país: um aumento de produção suficiente para garantir superávits comerciais e, consequentemente, a entrada de metais, ou tomar crédito no exterior para conseguir importar metais (Mauá, 2011b, p. 293). Em sua visão, no Brasil, a primeira hipótese seria difícil de alcançar; a segunda, uma estultice, pois os empréstimos externos para manter o valor da moeda, expediente utilizado pelos defensores da moeda metálica (Gambi, 2015a), só se justificariam se as circunstâncias econômicas do país fizessem esse capital permanecer por longo prazo, o que não era o caso, uma vez que o capital emprestado refluía assim que o câmbio se valorizava (Mauá, 2011b, p. 294). Assim, a moeda conversível em metal seria apenas o sonho dourado dos homens da escola metálica.

Finalmente, o fato de considerar a moeda metálica um dogma sustentado pela autoridade de economistas estrangeiros. O debate na Inglaterra, na França, no Estados Unidos e no Brasil indicavam que havia dúvidas quanto ao melhor sistema monetário e bancário a ser seguido (Mauá, 2011 b, p. 287) e isso desautorizava a escolha da conversibilidade metálica como única alternativa.

Para Mauá, o fundamental era conseguir uma oferta monetária suficiente para atender, sem excessos, as transações de todo o Brasil. Era importante considerar as necessidades das províncias e não só da Corte, ponto que Mauá e Souza Franco criticavam em seus adversários defensores da moeda metálica, como Tavares Bastos e Itaboraí (Mauá, 2011a, p. 210). Nesse sentido, o papelmoeda poderia ser de qualquer sorte, mas é evidente que o papel conversível em metal, além de imobilizar recursos que poderiam ser destinados à produção, não teria flexibilidade suficiente para atender aquela exigência, restando, portanto, o papel conversível em ativos ou mesmo inconversível.

Numa analogia com as ferrovias, Mauá dizia que não importava se os vagões fossem feitos de mogno ou pinho, o importante é que existissem em quantidade suficiente para transportar toda a mercadoria. Sem vagões suficientes não haveria transporte, assim como sem meio circulante suficiente não haveria transações. Em ambos os casos, a riqueza ficaria paralisada contra o interesse social (Mauá, 2011b, p. 302).

A moeda conversível seria preferível desde que houvesse amplos recursos para mantê-la. Porém, em circunstâncias especiais, essa moeda poderia ser temporariamente substituída com vantagem, e enfatiza Mauá “com grande vantagem mesmo”, pelo papel inconversível de bancos com grande capital e credibilidade (Mauá, 2011b, p. 283).

Apesar das divergências entre os estudiosos de Mauá, parece clara sua posição quanto à moeda. Ele se colocava como um convicto defensor do liberalismo e por isso buscava vincular o problema monetário à questão. Teoricamente, sustentava, em primeiro lugar, a moeda conversível em ativos 
que não o metal, pois ela não traria o inconveniente da imobilização de recursos e teria flexibilidade suficiente para acompanhar o aumento da demanda por moeda e crédito. Em caso de crise, em que a elasticidade dos títulos não acompanhasse a necessidade do crédito, a moeda inconversível seria o instrumento mais adequado para amenizar seus efeitos e manter a economia funcionando. Em outras palavras, conversibilidade em ativos que não o metal como regra e inconversibilidade como exceção.

De qualquer modo, o lastro metálico estaria descartado, posição que, de fato, o afastaria tanto de Souza Franco quanto da escola bancária inglesa. Entretanto, dada a situação excepcional da economia brasileira, que convivia com a escassez de metal, moeda e crédito, a moeda inconversível seria regra no Império e, segundo Mauá, teria prestado enorme serviço ao seu progresso econômico.

Se o metal ou outros ativos serviriam como base do valor da moeda conversível, o movimento de oferta e demanda expressaria o valor da moeda inconversível, portanto, esse valor só poderia se manifestar se houvesse liberdade bancária e pluralidade de emissão. A ausência de limite para as emissões era o principal argumento contrário à posição de Mauá e seus adversários enxergavam no abuso de emissão a causa principal das crises financeiras do Império (Gambi, 2015a). Como a emissão dos bancos costumava entrar em circulação como moeda, haveria necessidade de regulálas para melhor controlar a oferta monetária.

Mauá, contudo, acreditava que o próprio funcionamento do mercado com maior liberdade bancária seria suficiente para regular as emissões, ainda mais porque bancos locais, ao concentrarem informações sobre aqueles mercados específicos, saberiam definir com maior facilidade a oferta de moeda capaz de satisfazer a demanda (Mauá, 2011b, p. 290), ou seja, os bancos naturalmente emitiriam na medida da necessidade do comércio.

Na prática, isso significava que chegariam a uma oferta monetária adequada por meio da experimentação. Muito diferente dos defensores da moeda conversível em metal, para quem o indicador do valor da moeda seria o câmbio, e mesmo dos que advogavam a moeda conversível em outros ativos, que viam na taxa de juros o termômetro regulador. Mauá descartava o primeiro porque, como veremos, não via relação entre o valor da moeda nacional e do câmbio. E o segundo porque não expressava adequadamente a relação entre oferta e demanda de capital num país tão extenso e diverso quanto o Brasil. Assim, recomendava: "nas condições da existência especiais do nosso papel-moeda, não é possível arrancar da ciência dados positivos; experimente-se pois!” (Mauá, 2011b, p. 297).

Mauá não usa o termo, mas parece aplicar em sua análise a lei do refluxo (Glasner, 1992, p. 896), segundo a qual bancos privados não poderiam criar uma emissão inflacionária, porque o próprio mercado os induziria a oferecer a oferta de moeda que o público desejasse manter.15 Contudo, como já mencionado, Mauá (2011b, p. 287) chega a dizer que, apesar de se considerar sectário da ideia liberal, não defendia o livre arbítrio na matéria monetária e afirma pelo menos uma vez em $O$ meio circulante do Brasil a necessidade de leis restritivas que garantissem solidez à

\footnotetext{
${ }^{15}$ Parece diferente da Real Bills Doctrine: "Acreditamos que sim, e que o erro nasce da falsa ideia, aliás apregoada por alguns economistas de nota, que a moeda e ainda os papéis de crédito representam as transações em cuja liquidação intervém, quando são meramente a força motriz que atua para sua realização” (Mauá, 2011b, p. 291). Para a Real Bills, a oferta de moeda seria definida ex-post pelo volume das transações. Pela lei do refluxo, a oferta monetária poderia ser definida ex-ante pela demanda por moeda que, por sua vez, estaria ligada a transações realizadas ou a realizar. Esta última seria coerente com a visão da moeda inconversível como força motora das transações e não somente uma representação de valor como queriam os economistas clássicos (Cosentino, 2016).
} 
moeda. Falava no relatório da comissão de inquérito de 1859 em conter as emissões por meio de certos limites definidos em lei e em manter uma concorrência regulada por lei para evitar o abuso emissor (Brasil, 1860, p. 96). Essa era claramente a posição de Souza Franco (Schulz, 2013; Gambi, 2015b), mas não parece coerente com a posição de Mauá em diversas outras passagens de $O$ meio circulante e mesmo de seu depoimento à comissão de inquérito.

Nelas surgem muito mais condenações à intervenção do Estado na matéria. Ele separa habilmente leis preventivas e restritivas, dizendo que as primeiras são espúrias, pois impedem o atendimento adequado da demanda por moeda do comércio, e as últimas seriam necessárias para conter abusos. Porém, em $O$ meio circulante, refere-se ao "direito de se fazer tudo aquilo que a lei não proíbe, não tendo a lei o direito de proibir senão o que pode prejudicar a terceiros” (Mauá, 2011 b, p. 287) ou, ao criticar a atuação do governo imperial à época da lei dos entraves ${ }^{16}$ diz que coibir a emissão dos bancos "por meio de leis restritivas e garantidoras era a missão dos estadistas" (Mauá, 2011b, p. 287). No depoimento, diz que "a circulação de um papel bancário, bem garantido embora inconversível, uma vez que sua emissão seja contida por certos limites definidos em lei, é um grande bem" (Brasil, 1860, p. 96); que "o mais eficaz corretivo das emissões desregradas é a concorrência” e que o ideal seria a concorrência ilimitada, mas ressalva que o país ainda não estaria pronto para essa "conquista" (Brasil, 1860, p. 97).

Como também já indicamos, uma possível explicação para essas duas posições aparentemente dissonantes é a inserção política desse discurso num campo inóspito a extremismos e o objetivo de fundo de influenciar a política econômica do Império. Por mais que defendesse a liberdade bancária e a pluralidade de emissão, talvez quisesse evitar que suas ideias fossem interpretadas pelos adversários como a defesa do "carnaval financeiro".

Além disso, quando Mauá fala em leis restritivas parece ser referir à coibição do abuso na administração dos bancos e não à restrição formal às emissões (Mauá, 2011b, p. 289). Essa posição é muito mais coerente com alguém que via na emissão inconversível, ou pelo menos conversível em ativos que não o metal, a elasticidade suficiente para fomentar a produção e atender à demanda por moeda, sobretudo, do comércio.

Outra dissonância seria ver o defensor da pluralidade bancária ocupar a diretoria do Banco do Brasil criado em 1853 para ter o monopólio da emissão de moeda no país. Para ser justo nesse caso, é preciso considerar a conjuntura em que se deu a criação do Banco do Brasil. Mauá era o presidente de um dos bancos que se fundiram para sua criação e nada mais natural que ocupasse lugar na direção do novo banco. Mais do que isso, ele esperava mesmo ocupar a liderança na nova instituição, o que acabou não acontecendo (Guimarães, 2012; Gambi, 2015a). Em sua Autobiografia, Mauá disse que não seguiu suas convicções por condescendência, pois não queria contrariar Itaboraí, então ministro da Fazenda (Mauá, 2011a, p. 215). Fora do Banco do Brasil, ele arquitetou o Mauá, MacGregor cuja missão seria justamente expandir o crédito por meio de emissão, numa tentativa de contornar uma lei preventiva da época (Guimarães 2012; Gambi, 2015a).

Mauá reconhecia o problema da flutuação do valor da moeda em casos de emissão inconversível e destacava que não só os advogados da moeda metálica, como também os trabalhadores, acabavam por culpar a inconversibilidade pela inflação. Ele se defendia dessa crítica dizendo que

${ }^{16}$ A lei 1.083, de 22 de agosto de 1860, estabelecia a conversibilidade em ouro do mil-réis. 
os prejuízos causados em certos momentos se pagariam ao longo do tempo e, pela negativa, que a moeda metálica tampouco seria solução, porque gerava outros tipos de crise, piores até para o funcionamento da economia (Mauá, 2011b, p. 290).

A verdadeira força da moeda inconversível estaria na produção do país. O efeito das flutuações seria amenizado caso a moeda fosse emitida por países cuja renda estivesse apoiada em elementos econômicos e financeiros capazes de sustentar o valor legal estampado no papel no ato de sua emissão. E ilustra o poder da moeda inconversível ao dizer que "a história financeira mostranos o papel-moeda intervindo para salvar das maiores crises essas nacionalidades” (Mauá, 2011b, pp. 290-911).

Ao contrário do que indica Cláudio Ganns (2011, p. 101), é possível enxergar em Mauá uma apologia do uso da moeda inconversível no Brasil do século XIx, embora tivesse consciência de que poderia sofrer ataques de seus adversários políticos como os mencionados anteriormente. Ele reconhecia o peso da tradição da doutrina metálica e a condenação moral da emissão inconversível, daí o cuidado com o discurso. No entanto, não acreditava que a situação brasileira se encaixasse nessa doutrina e considerava os ataques sofridos por ele como preconceito teórico e desconhecimento da realidade nacional.

Diferentemente de outras experiências, a moeda inconversível estivera presente no Brasil desde a criação do primeiro Banco do Brasil (Mauá, 2011b, p. 291) e, ao ser utilizada para toda sorte de negócios, desde a compra de verduras até as mais altas operações financeiras, promovera um importante progresso econômico no país. Ela teria evitado sacrifícios que estariam além do alcance para superar as dificuldades nacionais caso houvesse circulação metálica, como a necessidade de um expressivo e rápido aumento da produção, a conversão de rendas derivadas da produção em metal ou a própria importação de metais (Mauá, 2011b, p. 297). Por isso considerava a lei dos entraves, de 1860, um grave erro de política econômica (Mauá, 2011b, p. 287).

A consciência da especificidade da experiência brasileira aparece com clareza quando sugere que o uso da moeda inconversível no país seria um caso peculiar de sucesso Sobre esse aspecto, indaga: não seria "um fenômeno digno de ser estudado, envolvendo como envolve, a solução de um problema de economia social?” (Mauá, 2011b, p. 292). Realmente, na época de Mauá, a circulação de valores no Brasil dependia da moeda inconversível e ela parece ter cumprido bem o seu papel, com o perdão do trocadilho. Segundo ele, ninguém poderia dizer que o país tinha experimentado um retrocesso econômico usando a moeda inconversível (Brasil, 1860, p. 96).

Mauá se esforçava para mostrar que a moeda inconversível era adequada às circunstâncias brasileiras e que, não poucas vezes, chegou a valer mais do que o próprio ouro, já que representava o crédito do Brasil na criação de riqueza (Mauá, 2011b, p. 295). Seria mesmo o potencial produtivo do país a base do valor de sua moeda inconversível. Para ele, qualquer papel de crédito assinado por quem fosse responsável e tivesse credibilidade na sociedade teria confirmado seu valor de face. A moeda inconversível assinada "pela nação brasileira" não seria inferior a nada. Apesar disso e das desvantagens mínimas do seu uso, dizia Mauá, ela sempre foi alvo de crítica por parte daqueles que, segundo ele, "se limitaram a ler o que a respeito escreveram alguns nomes autorizados, sem querer estudar os fatos que nos são relativos” (Mauá, 2011b, p. 293).

De fato, Mauá era crítico dos doutrinários inflexíveis e tentava contrapor as teorias econômicas da época à realidade brasileira (Mauá, 2011b, p. 281). Considerava a economia política tendo em vista sua necessidade de lidar com diversas questões e realidades distintas e a criticava por muitas 
vezes pretender explicar problemas específicos com generalizações impróprias. O que exporia a necessidade de rever certos postulados diante de outros contextos ou desconsiderá-los diante de sua inadequação (Mauá, 2011b, p. 282).

Isso não significava abandonar os princípios econômicos, o que seria "navegar sem bússola" (Mauá, 2011b, p. 285), mas adaptá-los às especificidades do Brasil, uma vez que, diante das circunstâncias, não conseguiriam explicar a nossa realidade peculiar, pois o Brasil teria sido o único país a dispensar completamente a moeda metálica. Assim, já que o país seria exceção, "como ir buscar na regra os meios de melhorar o instrumento de que nos servimos?” (Mauá, 2011b, p. 297).

Era assim que Mauá se contrapunha à autoridade teórica e utilizava-se da prática no contexto de uma realidade específica para avançar suas ideias e recomendações sobre a moeda e o crédito no Brasil. No final da década de 1870, Mauá recomendava, com base na experiência, dobrar a quantidade de meio circulante dentro de poucos anos. Esse tipo de recomendação sempre vinha acompanhado da prudência necessária para evitar o abuso, ressalva também comum em Souza Franco (Gambi, 2015b), mas essa proposta parecia menos arriscada depois da experiência da guerra do Paraguai.

Durante a guerra, houve grande emissão de moeda inconversível. Esperava-se que seu efeito fosse uma desvalorização mortal da moeda nacional, comparável ao caso dos assignats franceses. No entanto, a desvalorização e a inflação não vieram como esperado pelos defensores da moeda metálica e Mauá dizia que "os fatos vieram mais uma vez dar solene desmentido às previsões desses pregoeiros da ruína, que se evitava com o próprio fato por eles condenado!" (Mauá, 2011b, p. 301). Isso era, para ele, sinal da insuficiência de meio circulante, tanto que em maio de $18755^{17}$ o governo fez uma emissão especial para auxiliar os bancos de depósito.

Se o câmbio não se desvalorizou com a expansão emissionista durante a guerra, como seria esperado teoricamente por alguns, tampouco se valorizou com o recolhimento da emissão especial usada no auxílio aos bancos. Tais fatos foram mobilizados para sustentar suas ideias sobre o funcionamento do câmbio.

\section{CÂMBIO}

Para Mauá, ao contrário dos defensores da moeda metálica e partidários da escola monetária, a moeda não estava intimamente ligada ao câmbio. Ele tentou provar seu ponto tanto em $O$ Meio circulante do Brasil quanto em seu depoimento à comissão de inquérito sobre a crise de 1857 , no qual tratou especificamente da questão cambial.

Os fatos eram fundamentais para Mauá e ele se aferrava àqueles que insistiam em contradizer a teoria econômica que relacionava emissão e câmbio. Em $O$ Meio circulante, relembrou os anos de 1839, 1841 e 1843 quando houve aumento de emissão inconversível sem afetar, ou até mesmo melhorar, o valor da moeda.

Como a moeda no Brasil era inconversível, Mauá explicava esse resultado pelo valor dos produtos exportáveis, segundo ele o que realmente regulava o valor da moeda (Mauá, 2011b, p. 300). Os fatos referidos acima faziam Mauá questionar o valor prático das teorias em relação ao papelmoeda do Brasil, as quais, mesmo contradizendo a realidade, eram apoiadas por economistas "da maior pujança científica" (Mauá, 2011b, p. 303).

${ }^{17}$ Lei 2565 , de 29 de maio de 1875. 
Mauá reconhecia que definir o que determinava o câmbio não era uma questão trivial, havia confusão entre o que era essencial e acidental derivando-se daí conclusões equivocadas afirmadas como verdades por autoridades econômicas legítimas (Brasil, 1860, p. 93). Novamente, Mauá se rebelava diante dos argumentos de autoridade.

Se, para Mauá, o valor dos produtos exportáveis regulava o valor da moeda, definia também o curso do câmbio, pois interferia na oferta e demanda no mercado de cambiais. Se aumentassem os saques sobre as praças com as quais o Brasil mantinha relações comerciais, o câmbio se elevava, isto é, se valorizava; se diminuíssem, o câmbio declinava.

Com isso, Mauá voltava os olhos para a estrutura da economia brasileira, uma vez que a importação de manufaturados era paga majoritariamente com a exportação dos produtos agrícolas, cujas colheitas costumavam ser anuais. A baixa do câmbio apareceria quando estivessem presentes pelo menos um desses fatores: uma queda na produção agrícola; uma queda na demanda por esses produtos nos mercados consumidores e, consequentemente, a baixa de seus preços; um déficit comercial ou outras influências menores e transitórias (Brasil, 1860, p. 93).

Mauá entendia que, dada a diversidade de fatores que poderiam concorrer para uma pressão sobre a praça, seria difícil preveni-las por meio de legislação. Pelo contrário, dizia, medidas coercitivas à ação do crédito poderiam causar males mais graves do que os que se pretendia prevenir (Brasil, 1860, p. 98). O curso do câmbio seria sempre influenciado pelo nível de produção agrícola e pelo comércio externo, ainda que causas transitórias também pudessem interferir no seu valor. Era a mesma posição daqueles que, no debate monetário, não defendiam a moeda metálica, como Souza Franco (Gambi, 2015b). Interessante notar que, pelo menos no discurso, Mauá rejeitava categoricamente a especulação como causa de flutuações cambiais, dizendo que em trinta e quatro anos de experiência comercial no Rio de Janeiro nunca tinha visto "liga entre os sacadores para alta ou baixa do câmbio" (Brasil, 1860, p. 94).

A baixa dos preços dos produtos agrícolas brasileiros nos mercados consumidores teria sido, no diagnóstico de Mauá, a principal causa da crise de 1857 e não as emissões bancárias, como queriam os "sectários da escola restritiva" (Brasil, 1860, p. 93), não havendo "motivo para os gritos descompassados que levantam os sectários da escola restritiva contra as emissões bancárias, limitadas e garantidas como elas são entre nós" (Brasil, 1860, p. 95).

Não obstante, os adversários de Mauá usariam com habilidade a crise externa para imputar à política monetária expansionista de Souza Franco ${ }^{18}$ então ministro da Fazenda, a responsabilidade pela crise interna. Apesar dos esforços do ministro e do próprio Mauá para mostrar o contrário, ganhava força na imprensa e no governo o diagnóstico do excesso de emissão como causa da desvalorização cambial (Gambi, 2015a).

Mauá negava esse diagnóstico com veemência. Embora aceitasse, por princípio, que a emissão inconversível poderia influenciar no câmbio, na análise da realidade brasileira, e da crise de 1857 em particular, isso não seria aceitável. Segundo ele, para dizer que a emissão seria responsável pela baixa do câmbio era preciso mostrar: que a conversibilidade em metal era praticada antes da crise; que o meio circulante do Império nessa época era realmente superior às necessidades das transações; que não se deram então outras causas que, em épocas anteriores, em que a circulação consistia exclusivamente em papel moeda do Estado, produziram o mesmo resultado.

\footnotetext{
${ }^{18}$ Souza Franco restaurou a pluralidade emissora no Brasil em 1857, quando vigorava o monopólio de emissão do Banco do Brasil estabelecido em 1853.
} 
No entanto, recorrendo aos fatos, ninguém poderia negar que: a conversibilidade em metal não era praticada antes da crise, a não ser determinados momentos; que o meio circulante não era excessivo, porque a taxa de juros permaneceu estável; que os eventos de 1848 na França também derrubaram o preço dos produtos agrícolas brasileiros e, consequentemente, o câmbio, mesmo não havendo naquela altura emissão inconversível de bancos em circulação (Brasil, 1860, p. 95).

A pressão monetária no Brasil ocorreria como em qualquer outro lugar em função de grandes liquidações de cambiais e de épocas de colheita. Se não houvesse instituições de crédito para fornecer os recursos necessários para essas transações, a pressão se manifestaria com maior intensidade e, no caso brasileiro, como ocorria frequentemente entre novembro e dezembro de cada ano, atingiria proporções que poderiam elevá-la à categoria de crise (Brasil, 1860, p. 98).

Qualquer legislação preventiva teria pouco efeito contra as crises. Mauá acreditava que o próprio mercado as corrigiria e garantiria o retorno das operações regulares do comércio. As crises seriam, no final, "reações necessárias que, como as tempestades no mundo físico, restauram o equilíbrio dos componentes atmosféricos quando estes se acham em desarmonia entre si” (Brasil, 1860, p. 98).

Em síntese, para Mauá o câmbio no Brasil era determinado, em última instância, pela produção agrícola e pelas condições do mercado externo. As emissões, como explicado, não tinham relação com a desvalorização da moeda por serem inferiores às necessidades da economia na época. Ainda para afirmar seu ponto, Mauá diz que bastaria verificar o comportamento das emissões e do câmbio em outras épocas e não se encontraria um movimento proporcional e unidirecional entre as duas variáveis.

De tudo o que foi exposto até aqui, é possível dizer que Mauá negava a ortodoxia monetária da época, isto é, a emissão de moeda metálica; defendia a liberdade bancária com o intuito de expandir o crédito para a produção e o comércio; propunha a pluralidade de emissão em papel inconversível para estimular a produção e a circulação de mercadorias no Brasil; defendia a criação de um sistema de crédito bancário nacional; refutava a ideia de que as emissões influenciavam o câmbio, cuja explicação estaria nas flutuações de sua oferta e demanda, naquele momento específico resultado da deficiência das colheitas, estagnação das exportações, da depreciação desses produtos nos mercados consumidores e da importação excessiva. A clareza dessas ideias e a veemência de sua defesa, todavia, não eram suficientes para eliminar as práticas típicas de um liberal da Corte brasileira.

\section{CONSIDERAÇÕES FINAIS}

O confronto das ideias de Mauá sobre o progresso econômico; a moeda e o crédito; e o câmbio expostas nos três textos analisados neste artigo -depoimento à comissão de inquérito de 1859, $O$ meio circulante do Brasil e Autobiografia - com seus interesses privados e sua ligação com o Estado ilumina nesse personagem fascinante um típico exemplar do liberalismo brasileiro do século XIx.

Sem dúvida Mauá foi influenciado pelo ideal liberal da economia clássica inglesa 19 Vimos isso em sua crítica à intervenção do Estado nas questões econômicas, especificamente às medidas preventivas que amarravam ainda mais a oferta de moeda e o crédito no país. Por outro lado, Mauá era um homem da Corte, próximo de políticos influentes, tanto conservadores, quanto liberais, como Itaboraí e Souza Franco. Foi agraciado com os títulos de barão e visconde, e não usava meias

${ }^{19}$ Fernandes (1974, p. 13) aponta essa influência também nos discursos parlamentares de Mauá. 
palavras para solicitar o auxílio estatal para seus negócios, ainda que sempre com a justificativa de que atuava em nome do interesse nacional. Portanto, Mauá estava muito mais próximo do Estado do que se poderia supor a partir de sua defesa do liberalismo e do exemplo inglês.

Na literatura, Mauá é visto frequentemente como industrialista. Contudo, a documentação analisada revela que, em sua visão, a chave para solucionar os problemas da economia brasileira à época não se resumia à indústria, mas ao aumento da produção em geral, especialmente a agrícola, e no desenvolvimento do comércio, atividades mais condizentes com as circunstâncias do país. A produção era a base do valor da moeda inconversível e o determinante do câmbio. Como ele mesmo afirmava em seu depoimento, "uns querem muito ouro, outros muito papel. Eu pela minha parte quisera ver muito trabalho, muita indústria e muita produção” (Brasil, 1860, p. 99). Vale lembrar que o termo indústria referia-se a qualquer produção e não especificamente à industrial. Em momento algum fica clara a defesa da industrialização do país, apenas o estímulo à criação de indústrias que conseguissem sobreviver sem auxílio governamental, bem ao gosto liberal.

No fundo de sua argumentação sobre a moeda e o crédito, e tendo em vista sua forte percepção da peculiar realidade brasileira, parece-nos que Mauá era mesmo um defensor da liberdade bancária, da pluralidade de emissão e da moeda inconversível. Suas ideias nesses aspectos se mostraram coerentes nesses escritos e, de fato, o colocariam no debate no lado do papelismo puro. Destaquese a consciência de Mauá em relação às especificidades da economia brasileira e à necessidade de recepção crítica das teorias estrangeiras.

Não obstante, vale dizer que a defesa de um papelismo puro seria especialmente conveniente ao seu negócio bancário. Se a credibilidade do emissor era a fiadora do valor da moeda fiduciária, esse requisito não lhe faltaria na praça e daria motivo para pensar que a emissão de seu banco se valorizaria diante da concorrência, mecanismo que, segundo ele, deveria regular as emissões. A experiência da emissão de vales do seu Banco do Brasil de 1851 reforçaria esse pensamento. Mauá propunha, então, um jogo aparentemente livre, mas do qual sabia que sairia vencedor.

Em síntese, entre o discurso em defesa do liberalismo clássico e a atuação próxima do Estado em seus negócios, Mauá foi capaz de apresentar um conjunto de ideias coerente e adaptado à realidade nacional em defesa da liberdade bancária e da moeda fiduciária. As dissonâncias de sua posição na questão monetária, reveladas no contraponto de Alberto de Faria e Cláudio Ganns, devem-se mais, a nosso ver, às possibilidades do debate político da época. Para ser mais influente nesse debate e na política econômica da época, seria mais conveniente não externar qualquer ideia mais extrema e se posicionar pragmaticamente entre a moeda inconversível e os princípios da escola bancária inglesa.

\section{REFERÊNCIAS}

Barroso, G. (1938). História secreta do Brasil. Terceira parte: a maioridade de D. Pedro II à proclamação da República. Rio de Janeiro: Civilização Brasileira.

Besouchet, L. (1978). Mauá e seu tempo. Rio de Janeiro: Nova Fronteira.

Brasil. Ministério da Fazenda. (1860). Relatório da comissão de inquérito nomeada por aviso do Ministério da Fazenda de 10 de outubro de 1859. Rio de Janeiro: Ministério da Fazenda.

Caldeira, J. (1995). Mauá: empresário do Império. São Paulo: Companhia das Letras.

Carneiro, E. A. (1965). Mauá. Rio de Janeiro: Departamento Administrativo de Serviço Público.

Carvalho, J. M. (1997). Mauá e a ética Saint-Simoniana. Londrina: Universidade Estadual de Londrina. 
Cosentino, D. V. (2016). Formação do pensamento econômico brasileiro no século XIX (Tese de Doutorado). Universidade de São Paulo, Brasil. DOI: 10.11606/T.8.2016.tde-22082016-113828

Faria, A. (1933). Mauá: Irineu Evangelista de Souza, barão e visconde de Mauá, (1813-1889). São Paulo: Companhia Editora Nacional.

Fernandes, S. (1974). Mauá, o economista do Império: Análise de sua crítica científica ao padrãoouro. Revista Brasileira de Economia, 28(2), 3-28.

Fonseca, P. C. e Mollo, M. L. (2012). Metalistas x papelistas: origens teóricas e antecedentes do debate entre monetaristas e desenvolvimentistas. Nova Economia, 22(2), 203-233.

Furtado, C. (2007). Formação econômica do Brasil. São Paulo: Companhia das Letras.

Gambi, T. F. R. (2015a). As ideias de Bernardo Souza Franco sobre a questão bancária nos níveis regional e nacional: Pará-Brasil (1845-1848). En 5th Latin American Conference of the History of Economic Thought. Chile: European Society for the History of Economic Thought.

Gambi, T. F. R. (2015b). O Banco da Ordem: política e finanças no Império brasileiro (1853-1866). São Paulo: Alameda.

Ganns, C. (2011). Prefácio e anotações à autobiografia de Mauá. En I. E. Mauá (ed.), Autobiografia. Brasília: Senado Federal.

Glasner, D. (1992). The Real-Bills Doctrine in the Light of the Law of Reflux. History of Political Economy, 24(4), 867-894. DOI: 10.1215/00182702-24-4-867

Gremaud, A. P. (1997). Das controvérsias teóricas à política econômica: pensamento econômico e economia brasileira no segundo Império e na Primeira República (1840-1930) (Tese de Doutorado). Universidade de São Paulo, Brasil.

Guimarães, G. G. (2012). A presença inglesa nas finanças e no comércio no Brasil imperial: os casos da Sociedade Bancária Mauá, MacGregor Eீ Cia. (1854-1866) e da firma inglesa Samuel Phillips Eீ Cia. (1808-1840). São Paulo: Alameda.

Kindleberger, C. P. (2000). Manias, pânico e crashes: um histórico das crises financeiras. Rio de Janeiro: Nova Fronteira.

Lima, H. F. (1976). Três industrialistas brasileiros: Mauá, Rui Barbosa, Roberto Simonsen. São Paulo: Alfa-Omega.

Macedo, J. M. (1876). Anno biographico brazileiro (vol. 3). Rio de Janeiro: Typographia e Lithographia do Imperial Instituto Artistico.

Martinho, L. M., e Gorenstein, R. (1992). Negociantes e caixeiros na sociedade da Independência. Rio de Janeiro: Secretaria Municipal de Cultura, Turismo e Esportes.

Mauá, I. E. (2011a). Autobiografia (C. Ganns, ed.). Brasília: Senado Federal.

Mauá, I. E. (2011b). O meio circulante do Brasil. Em C. Ganns (ed.), Autobiografia. Brasília: Senado Federal.

Momesso, B. P. (2007). Indústria e trabalho no século XIX: o estabelecimento de Fundição e Máquinas de Ponta dAreia (Dissertação de mestrado). Universidade Federal Fluminense, Brasil.

Motta, M. S. (2000). O relato biográfico como fonte para a história. Vidya, 19(34), 101-122.

Nabuco, J. (1998). Um estadista do Imperio. São Paulo: Topbooks.

Novais, F. e Arruda, J. J. A. (2003). Prometeus e Atlantes na forja da nação. Economia e Sociedade, 12(2), 225-243.

O'Brien, D. P. (2007). The development of monetary economics: a modern perspective on monetary controversies. Cheltenham: Edward Elgar.

Paim, A. (1968). Cairu e o liberalismo econômico. Rio de Janeiro: Tempo Brasileiro. 
Petratti, P. (1977). A instituição da The São Paulo (Brazilian) Railway Limited (Dissertação de Mestrado). Universidade de São Paulo, Brasil.

Rebello, E. C. (1975). Mauá e outros estudos. Rio de Janeiro: Livraria São José.

Rocha, A. P. (1996). A economia política na sociedade escravista: um estudo dos textos econômicos de Cairu. São Paulo: Editora Hucitec.

Saes, F. A. M. (1986). Crédito e bancos no desenvolvimento da economia paulista: 1850-1930. Sâo Paulo: Universidade de São Paulo.

Saes, F. A. M. (1987). Mauá e sua presença na economia brasileira do século xix. En O. Cropani, Barão de Mauá: empresario e político. São Paulo: Bianchi.

Schulz, J. (2013). Souza Franco and Banks of Issue as Engines of Growth. História e Economia. Revista Interdisciplinar, 11(1), 15-38.

Silva, J. M. (2003). Memórias do meu tempo. Brasília: Senado Federal.

Souza, R. R. (2005). Exposição aos credores: a escrita como redenção. Sceculum. Revista de História, $13,78-89$.

Souza, R. R. (2007). Mauá e a tradição de modernização industrial no Brasil (Dissertação de Mestrado). Universidade Federal de Minas Gerais, Brasil.

Souza, R. T., e Fossatti, N. C. (eds.). (2013). Mauá: Paradoxos de um visionário. Obra comemorativa de 200 anos de nascimento de Visconde de Mauá. Porto Alegre: Letra \& Vida.

Taunay, A. E. (1948). Memórias do visconde de Taunay. São Paulo: Instituto Progresso Editorial.

Tavares, L. H. D. (1988). O capitalismo no comércio proibido de escravos. Revista do Instituto de Estudos Brasileiros, 28, 37-52. DOI: 10.11606/issn.2316-901X.v0i28p37-52

Vasconcellos, B., e Smith, B. (1918). Archivo nobiliarchico brasileiro. Lausanne: Imprimerie La Concorde.

Villela, A. (1999). The political economy of money and banking in Imperial Brazil, 1850-1870 (PhD Thesis). The London School of Economics and Political Science, Londres. 